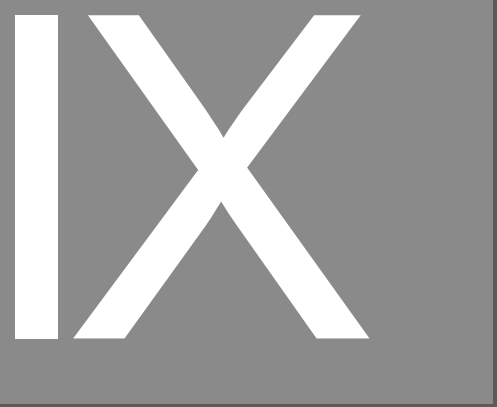

\title{
UMA PERCEPÇÃO PESSOAL DA PREGAÇÃO SOBRE O DEUS CRIADOR NO DECORRER DO TEMPO
}

\section{A personal perception of preaching about God the Creator over time \\ Sociedad Creacionista Brasilera, Brasil}

\section{Ruy Carlos de Camargo Vieira}

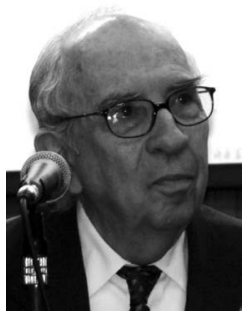

Ingeniero Mecánico y Eléctrico por la Escola Politecnica de la Universidade de São Paulo, Brasil. Catedrático emérito de la Universidade de São Paulo (USP). Trabajó en la Comissão de Especialistas do Ensino de Engenharia do Ministério da Educação e Cultura especialista. Miembro del Conselho da Agência Espacial Brasileira. Presidente y fundador de la sociedad creacionista brasilera. Profesor itinerante, escritor prolífico tanto en revistas científicas como nacionales y ponente internacional. 


\section{Resumen}

El siguiente artículo revela la percepción del investigador sobre el concepto de Dios como Creador a la luz de los escritos bíblicos, asimismo, se analiza el impacto personal que causó este tema en la vida del investigador, del mismo modo se sintetiza el concepto y percepción de Dios como Creador en la historia antigua, en los inicios del cristianismo, y la percepción de este concepto en los "últimos días"; todo ello contrastado con la cosmovisión evolucionista.

Palabras clave: Creacionismo, evolucionismo, método científico, diseño inteligente.

\section{Resumo}

O artigo a seguir revela a percepção do pesquisador do conceito de Deus como criador à luz dos escritos bíblicos também discute o impacto pessoal que fez isso na vida do pesquisador, da mesma forma resume o conceito ea percepção de Deus como criador na história antiga, no início do cristianismo, ea percepção deste conceito nos "últimos dias", tudo o que contrasta com a visão de mundo evolucionária.

Palabras llave: Criacionismo, evolução, método científico, projeto inteligente.

\section{Abstract}

The following article reveals the researcher's perception of the concept of God as creator in the light of the biblical writings also discusses the personal impact that caused this in the life of the researcher, similarly summarizes the concept and perception of God as creator in ancient history, in the beginning of Christianity, and the perception of this concept in the "last days", all of which contrasted with the evolutionary worldview.

Key words: Creationism, evolution, scientific method, intelligent design. 


\section{Introdução}

Há 61 anos, selei minha decisão de aceitar a revelação de Deus dada em Sua Palavra, a Bíblia, atendendo aos apelos do Espírito Santo que me havia convencido tanto do pecado, como da justiça e do juízo.

- Do pecado, porque me havia levado a crer em Cristo como o Cordeiro de Deus que tira o pecado do mundo, nos perdoa e transforma nosso coração retirando-nos das trevas e levando-nos para a Sua maravilhosa luz.

- Da justiça, porque me havia levado a compreender o Plano da Salvação, onde a justiça e a misericórdia se encontram no sacrifício de Cristo - o Messias prometido - cujo sangue foi derramado como o de uma vítima inocente, resgatando-nos de nossa vã maneira de viver.

- Do juízo, porque me havia levado à certeza de que se aproximava o fim deste breve intervalo de tempo em decurso desde a queda do ser humano - originalmente criado perfeito por Deus - até a restauração de todas as coisas, e de que deveríamos "erguer a nossa cabeça, pois a nossa redenção está próxima".

E sentia, ainda, que muitas coisas mais Deus tinha para me dizer, mas ainda não era o momento de serem reveladas por não ter chegado o tempo oportuno.

Passados esses 61 anos, creio ter sido providencial a oportunidade que se me apresenta agora, para - em breves palavras - render graças a este maravilhoso Deus Criador compartilhando com os leitores a percepção que dEle tenho tido, "como a luz da aurora que vai brilhando cada vez mais em direção ao dia perfeito" (Provérbios 4:18).

\section{Impactos da percepção do deus criador em minha vida}

Dada a influência da educação secular sobre minha mente no decorrer dos anos da formação escolar até o início da carreira universitária, quando então comecei a me familiarizar com a mensagem da salvação revelada na Bíblia, senti vários impactos, que gradativamente me levaram a mudar minha concepção de mundo.

Os primeiros impactos foram de natureza histórica. O estudo das profecias apontava indubitavelmente para Cristo como o Messias prefigurado nas Escrituras, e de maneira particular revelado na cadeia profética do Livro de 
Daniel, capítulos 8 e 9, interligada com notáveis acontecimentos pertinentes relatados na história antiga.

Em seguida, mas na realidade paralelamente, ocorreram impactos de natureza científica, pois o estudo do relato da Criação apontava também indubitavelmente para uma semana literal, em intima conexão com a observância do sábado, como memorial dessa fantástica obra criadora. E, da mesma forma, o relato do Dilúvio indubitavelmente apontava para uma catástrofe de extensão mundial.

Entretanto, embora os impactos de natureza histórica tivessem exercido notável papel para a consolidação da minha fé em Cristo como o Salvador e no plano divino para a restauração de todas as coisas, em meu íntimo os impactos de natureza científica a respeito da Criação e do Dilúvio permaneciam exigindo ainda alguma explicação adicional.

Em resumo, era tão somente pela fé que eu podia entender que "foi o universo formado pela palavra de Deus, de maneira que o visível veio a existir das cousas que não aparecem" (Hebreus 11:3), e que, "de longo tempo, houve céus bem como terra, a qual surgiu da água e através da água pela palavra de Deus, pela qual veio a perecer o mundo daquele tempo, afogado em água" (II Pedro 3:5-6).

Não obstante, sem minimizar a importância da fé para a aceitação daquilo que não foi revelado, eu sentia a necessidade de me apoiar também em evidências e argumentação científica para fazer face ao ceticismo de meus colegas de estudo na Universidade quanto a esses dois eventos tão significativos no contexto dos planos de Deus - A Criação e o Dilúvio.

Dentro deste panorama, preocupava-me a questão de como teria ocorrido, no decorrer do tempo, a degradação e a deturpação da verdade inicialmente transmitida pelo próprio Criador ao homem, mantida pelos patriarcas da linhagem de Abel até Noé e Abraão e posteriormente incorporada na revelação das Escrituras Sagradas.

Deixando a questão do Dilúvio para outra oportunidade, pretendo aqui trazer subsídios para evidenciar a continuidade da percepção de um Deus Criador no decorrer do tempo, não obstante a degradação e deturpação dessa percepção. Em síntese, as evidências a favor da percepção desse Deus Criador giram em torno do conflito entre duas posições antagônicas para a explicação da natureza ao nosso redor - a que defende o planejamento decorrente de desígnio e propósito de um Ser Criador, e a que defende simplesmente a atuação de um acaso cego.

Esta segunda posição passou hoje a ser dominante nos meios de comunicação e no sistema educacional secular, os quais cada vez mais 
intensamente continuam a contribuir para a degradação e a deturpação da revelação dada pelo Criador, influindo especialmente na (má) formação das gerações mais novas.

Passarei, assim, a tecer algumas considerações a respeito da preservação da percepção desse Deus Criador no decorrer da história antiga e na pregação cristã desde os tempos apostólicos até os nossos dias atuais.

\section{A percepção do deus criador na história antiga}

Após o Dilúvio, no início de um mundo novo, os depositários da revelação de Deus foram Noé, sua família, e seus descendentes.

Com a dispersão dos povos, e seu gradativo afastamento do tronco comum inicial, a verdade original transmitida por tradição oral foi sendo degradada e deturpada, apresentada na forma de tradições e lendas, particularmente relacionadas com os dois grandes eventos universais - a Criação e o Dilúvio. Em relação ao primeiro desses eventos, pesquisando-se as crenças dos povos mais antigos sobre os quais existem registros históricos escritos, não é difícil concluir que todos eles, sem exceção, mantinham a crença em uma divindade suprema - o Deus Criador!

Com este pano de fundo, pretendo agora fazer um pequeno resumo histórico do conflito entre a posição que defende o Planejamento e um Supremo Ser Criador, e a posição que defende simplesmente a atuação do Acaso para explicar a natureza que nos cerca e na qual nos inserimos. Para isso, recorrerei com freqüência a citações do excelente trabalho de pesquisa de Bill Cooper (Membro do Conselho do Creation Science Movement, a mais antiga entidade criacionista moderna, sediada na Inglaterra) intitulado "After the Flood", traduzido por mim para o Português e publicado pela Sociedade Criacionista Brasileira. As citações que serão feitas, constantes desse trabalho, serão indicadas na Bibliografia.

A título de observação preliminar, parece que o pensamento popular hoje jamais tem levado em conta a possibilidade de que outros povos, além dos Hebreus, realmente tivessem tido conhecimento do Deus Criador, Seu poder e atributos, bem como que essa percepção pudesse ter existido e florescido, durante séculos, sem qualquer vínculo com a revelação expressa nas Escrituras.

Assim, foi com um misto de surpresa e alegria que descobri a excelente fundamentação apresentada por Bill Cooper exatamente sobre o fato de que o conhecimento e a apreciação profundos de um Deus Criador 
eterno e todo-poderoso, a Sua paternidade de toda a raça humana, e os Seus atributos infinitos, encontram-se nos escritos de vários historiadores no mundo antigo, bem como nos ensinamentos dos mais antigos filósofos.

Tão profundos eram a concepção e o conhecimento desse Deus entre certos povos pagãos do mundo antigo, e em particular no mundo grecoromano, que até mesmo foi então iniciada a controvérsia (que deveria manterse acesa durante muitos séculos) entre os que propagavam e preservavam aquele conhecimento de Deus como Criador, e os que procuravam destruí-lo, atribuindo a criação do universo a forças puramente naturais.

Por exemplo, dos escritos do taoista Lao-tzé, que floresceram na China do sexto século a.C., podemos extrair a seguinte afirmação profunda relativa à existência e aos atributos de Deus: "Antes do tempo, e durante todo $o$ tempo, tem existido um Ser com existência própria, eterno, infinito, completo, onipresente. ... Para além deste Ser, antes do início, não havia nada." ${ }^{11}$

Dificilmente poderá ser negado que esse mesmo conceito de um Deus Criador realmente tivesse existido com igual profundidade em muitas outras civilizações antigas, por exemplo no Egito, conforme testifica o seguinte texto antigo de Hierápolis: "Eu sou o criador de tudo que existe... que surgiu a partir de minha boca. Os céus e a terra não existiam, nem tinha sido criada a erva do campo nem as coisas que rastejam. Eu as fiz surgir do abismo primordial, a partir de um estado de não existência ...." ${ }^{2}$

Entre os antigos gregos, temos na "Teogonia" de Hesíodo (oitavo século a.C.) um relato da criação do mundo que mantém semelhanças notavelmente próximas e irretorquíveis com o relato de Gênesis: "Antes de tudo veio à existência o Vazio ... em seguida, a Terra. ... Do Vazio veio a escuridão ... e da Noite veio a Luz e o Dia ....".

Xenófanes, que viveu cerca de dois séculos depois de Hesíodo, mantinha uma visão ainda mais sublime do Criador:

"Homero e Hesíodo deram aos deuses todos os atributos que entre os homens são vergonhosos e censuráveis - roubo, adultério e mentira. ... Porém, existe um Deus, maior entre os deuses e os homens, não semelhante aos mortais quer em forma quer em pensamento ... que vê como um todo, pensa como um

${ }^{1}$ Lao-Tzé. Tao-te-ching, tr. Léon Wieger. Versão inglesa por Derek Bryce, 1991. Llanerch Plublishers. Lampeter. p. 13. Além desta citação, não se pode ignorar a história da Criação e do Dilúvio revelada nos caracteres chineses antigos, hoje redescoberta por exemplo nos livros de autoria de Ethel R. Nelson que vêm sendo traduzidos e publicados pela SCB (Sociedad Creacionista Brasilera).

${ }^{2}$ Paráfrase, feita por Bill Cooper, da tradução literal de Wallace Budge em The Gods of the Egyptians. Vol. 1. Dover. New York. 1969. pp. 308-313.

${ }^{3}$ Hesíodo. Theogony. (tr. Norman Brown. 1953). Bobbs-Merril Co. New York. p. 15 
todo. ... Ele permanece sempre no mesmo estado, sem qualquer mudança. ... E longe de se fatigar, governa tudo com sua mente". (Barnes, 1987. p.42).

O conceito desse Deus Criador inefável, por exemplo, permeou o pensamento de Platão, que procurou substituir aqueles conceitos de Hesíodo sobre a Criação por outros mais razoáveis, sem dúvida com base em conceitos filosóficos bem anteriores aos de Hesíodo, certamente bem mais profundos:

"Ressaltemos, portanto, a razão pela qual o grande modelador deste universo dinâmico realmente o modelou. Ele era bom, e o que é bom não possui em si qualquer partícula de cobiça; sendo, portanto, isento de cobiça, ele desejava que todas as coisas fossem tão semelhantes a ele quanto possivel. É este um princípio válido para a origem de um mundo dinâmico, tanto quanto podemos descobrir a partir da sabedoria humana ...".4

Texto este no qual se pode perceber um eco da declaração de Gênesis: "E viu Deus que tudo era muito bom".

Por outro lado, através de Plutarco, ficamos conhecendo a proposição de Anaximandro, de que "... originalmente, os seres humanos nasceram de animais de diferentes espécies ..." defendendo, assim, ser "natural" o principio criativo que teria trazido o universo à existência.

Platão, porém, falando dos materialistas - como Anaximandro - como se fossem uma nova linhagem pouco prometedora de pensadores que acabavam de ter entrado em cena, declara: "Algumas pessoas, acredito, explicam todas as coisas que vieram a existir, todas as coisas que hoje estão vindo a existir, e todas as coisas que virão a existir no futuro, atribuindo-as à natureza, a coincidências ou ao acaso". ${ }^{6}$

O modelo de Platão, ao contrário, era um conceito totalmente mais elevado. Para ele, o Criador fez o caos tornar-se ordem simplesmente porque fazer isso era inerente à Sua boa natureza e ao Seu bom desejo. Deus preferia a ordem ao caos, e para assegurar a manutenção dessa ordem, tudo o que Ele criou foi feito de conformidade com uma configuração eterna e perfeita, o que Platão exprimiu em sua justamente famosa "Teoria das Formas".

Epicuro defendeu a posição contrária, em torno do fim do quarto século a.C., com uma cosmologia cujos efeitos deveriam reverberar por todo o mundo romano vindouro, durante muitos séculos. $E$, de fato, até hoje ainda

\footnotetext{
${ }^{4}$ Platão. Timaeus and Criteas. (tr. Desmond Lee. 1965). Penguin Classics. Harmondsworth p. 42.

${ }^{5}$ Ibid. p. 73.

${ }^{6}$ Platão. The Laws. (tr. Trevor Saunders. 1970). Penguin Classics. Harmondsworth. p. 416.
} 
ela sobrevive nos elementos de várias filosofias modernas. Em particular, o atomista Epicuro argumentava que era insuficiente advogar a criação divina do universo, como fez Platão, "a partir da hipótese de um cosmo bem ordenado, simplesmente porque o cosmo, a seu ver, não era bem ordenado". (Lund, 1976). ) - o cosmo teria se desenvolvido através de uma longa série de acidentes, talvez infinita, a partir de colisões aleatórias de átomos.

Longe de eliminar o Criacionismo, o Epicurismo simplesmente serviu para reagrupar as fileiras criacionistas no sentido de uma melhor definição de seus pontos de vista, tendo assim se levantado a Escola Estóica de pensamento para enfrentar o desafio do materialismo epicurista.

O Estoicismo foi fundado por Zenão em torno de 308 a.C., com uma concepção do Criador muito mais profunda do que até então havia prevalecido no pensamento grego, seja o de Hesíodo, Xenófanes ou mesmo Platão.

"Se existe algo na natureza que a mente humana, a inteligência, a energia e a força humanas não podem criar, então o criador dessas coisas deve necessariamente ser um ente superior ao homem. Os corpos celestes em suas órbitas eternas certamente não poderiam ser criados pelo homem. Eles, portanto, devem ter sido criados por um ser superior ao homem. ... Somente um tolo arrogante imaginaria que nada houvesse, no mundo todo, maior do que ele próprio. Logo, deve existir algo maior do que o ser humano. E esse algo deve ser Deus".?

Um estóico posterior, Cícero, foi quem deu a esse conceito talvez sua mais elevada expressão nos tempos pré-cristãos, e pelo menos algumas de suas palavras merecem ser citadas:

"Ao observarmos um gnomon (relógio de sol) ou uma clepsidra (relógio de água), vemos que eles indicam o tempo de maneira propositada, e não por acaso. Como podemos imaginar, então, que o universo como um todo seja destituído de propósito e inteligência, ao abarcar tudo, incluindo esses próprios artefatos e seus artífices? Nosso amigo Possidônio, como sabemos, recentemente elaborou um globo que, em seu movimento de rotação, mostra o movimento do Sol, das estrelas e dos planetas, dia e noite, exatamente como eles aparecem no céu. Ora, se alguém tomasse esse globo e o mostrasse aos habitantes da Bretanha ou da Cítia, algum desses bárbaros deixaria de perceber que ele era o produto de uma inteligência consciente?"8

p. 130 .

${ }^{7}$ Cícero. On the Nature of the Gods. (tr. Horace McGregor. 1988). Penguin Classics. Harmondsworth,

${ }^{8}$ Cícero. p. 159. 
Com essas palavras maravilhosamente simples (posteriormente, muitos séculos após, parafraseadas pelo "bárbaro" bretão William Paley...) Cícero proclama a idéia que ainda hoje é a mais difícil de ser refutada pelos materialistas, pois é quase impossível explicar de maneira convincente, por exemplo, a indescritível complexidade dos organismos vivos, ou simplesmente de partes suas, como sendo resultado do acaso cego, ou de eventos aleatórios.

Cícero simplesmente não podia concordar com o ponto de vista epicurista atomista de Lucrécio:

"Nos céus nada há de acidental, nada arbitrário, nada fora de ordem, nada errático. Tudo é ordem, verdade, razão, constância. ... Não posso compreender essa regularidade nas estrelas, essa harmonia do tempo e do movimento em suas imensas órbitas durante toda a eternidade, a não ser como a expressão de razão, mente e propósito. ... O seu movimento constante e eterno, maravilhoso e misterioso em sua regularidade, declara o poder inerente de uma inteligência divina. Se algum homem não pode sentir o poder de Deus ao olhar para as estrelas, então duvido que seja capaz de qualquer outro sentimento também. ${ }^{9}$

Não é realmente surpreendente alguém pôr-se a acreditar que um número imenso de partículas sólidas e separadas, pudesse, mediante colisões aleatórias, e movidas tão somente pela força de seu próprio peso, trazer à existência um mundo tão belo e maravilhoso? Se alguém pensa que isso é possivel, não vejo porque também não pudesse pensar que, se um número infinito de letras, dentre as vinte-e-uma do alfabeto, feitas de ouro ou do que quer que seja, fosse misturado e lançado no chão, pudessem elas cair de tal maneira que formassem, por exemplo, o texto completo dos "Anais" de Ênio. De fato, duvido que o acaso permitisse que as letras formassem sequer um único verso dos "Anais"! 10

Não deixa de ser impressionante como que o pensamento estóico, manifesto nas declarações de Cícero (nos albores da "plenitude dos tempos" preconizada em Gálatas 4:4), apontava para um Ser Supremo, um Criador cujos propósitos se manifestassem no planejamento das coisas criadas. Assim, cerca de duas décadas antes de sobrevirem os acontecimentos profetizados na Escritura a respeito da vinda do Messias em cumprimento ao Plano da Salvação, já o ambiente da Filosofia no Império Romano era propicio para receber a semente do Evangelho que seria lançada pouco depois pelos Apóstolos.

\footnotetext{
${ }^{9}$ Cícero. pp. 144-145.

${ }^{10}$ Cícero. p. 161.
} 
Ruy Carlos de Camargo Vieira

Fica claro, em Atos 17:18 que filósofos estóicos e epicuristas, em outras palavras, os criacionistas e evolucionistas da época, interessaramse em discutir com Paulo o assunto do planejamento e acaso que envolvia "o Deus que fez o mundo e tudo que nele existe" (v. 24). Embora a questão da restauração do mundo caído, com a ressurreição dos mortos, os tivesse desinteressado, vemos, entretanto, no versículo 34, que certamente alguns estóicos tivessem sido despertados para este último assunto, crendo e agregando-se aos primeiros conversos ao Cristianismo.

\section{A percepção do deus criador desde o início do cristianismo}

No início do Cristianismo, os apóstolos e discípulos empenharam-se de corpo e alma na pregação das "novas de grande alegria", que incluíam a lembrança de aspectos específicos do grande Plano da Redenção a serem proclamados a "todas as tribos, nações e línguas" incluindo principalmente o testemunho da morte e ressurreição de Cristo, o Messias tão esperado, mas rejeitado pelas classes dominantes judaicas.

Não faria sentido, entretanto, essa pregação, sem a devida conexão com a lembrança da criação de um mundo perfeito que se afastara do Criador em virtude de sua desobediência, o que ocasionou a entrada do pecado nesse mundo, com a degradação e a morte ocorridas em conseqüência dessa separação de Deus, desvirtuando os propósitos originais do Criador. Nesse contexto, a pregação da morte expiatória do Messias e a promessa da restauração de todas as coisas, demonstrando o indescritivel amor de Deus para com as Suas criaturas, entrelaçaram-se com os Seus propósitos como Criador, a serem cumpridos no grandioso Plano da Redenção centralizado agora na ressurreição de Cristo.

Assim, a pregação da mensagem sobre o Deus Criador é encontrada no texto bíblico em diferentes ocasiões específicas, culminando enfaticamente com a pregação do "Evangelho Eterno" mencionada profeticamente para os dias finais da história deste mundo. As passagens seguintes resumem como foi pregada no início do Cristianismo a mensagem sobre o Deus Criador, em algumas ocasiões específicas:

- S. João 1:1-3 - No princípio era o Verbo, e o Verbo estava com Deus, e o Verbo era Deus. Ele estava no princípio com Deus. Todas as coisas foram feitas por intermédio dEle, e sem Ele nada do que foi feito se fez. 
- Atos 4:24 - Ouvindo isto, unânimes, levantaram a voz a Deus, e disseram: Tu, soberano Senhor, que fizeste o céu, a terra, o mar e tudo o que neles há.

- Atos 14:15 - ... Nós vos anunciamos o evangelho para que destas coisas vãs vos convertais ao Deus vivo, que fez o céu, a terra, o mar e tudo que neles há.

- Atos 17:23-24 e 26 - ... Pois esse que adorais sem conhecer é precisamente Aquele que eu vos anuncio: o Deus que fez o mundo e tudo o que nele existe, sendo Ele Senhor do céu e da terra ... de um só fez toda a raça humana para habitar sobre toda a face da terra.

- Romanos 1:29 - Porque os atributos invisíveis de Deus, assim o Seu eterno poder, como também a Sua própria divindade, claramente se reconhecem, desde o princípio do mundo, sendo percebidos por meio das coisas que foram criadas.

- Efésios 3:8-9 - A mim ... me foi dada esta graça de pregar aos gentios o evangelho das insondáveis riquezas de Cristo e manifestar qual seja a dispensação do mistério, desde os séculos, oculto em Deus, que criou todas as coisas.

- Colossenses 1:15-16-Ele é a imagem do Deus invisível, o primogênito de toda a criação, pois, nEle, foram criadas todas as coisas, nos céus e sobre a terra, as visíveis e as invisíveis. ... Tudo foi criado por meio dEle e para Ele.

- Hebreus 11:3 - Pela fé, entendemos que foi o Universo formado pela palavra de Deus, de maneira que o visível veio a existir das coisas que não aparecem.

A pregação apostólica continuou ganhando pessoas que nela creram e foram sendo agregadas à Igreja. A crença nessa nova fé cristã, paralelamente à crença no Deus Criador que deveria restaurar todas as coisas, aos poucos foi sendo expressa em breves palavras que passaram a constituir uma declaração de fé, usualmente uma forma de explicitar, por ocasião do batismo, a nova fé que estava sendo abraçada. 
Assim, vários trechos hoje incorporados no texto do Novo Testamento, apresentam verdadeiras declarações de fé fragmentárias que aparentemente teriam sido posteriormente coligidas e codificadas, vindo a formar o chamado "Credo Apostólico". Um exemplo dessas declarações fragmentárias é o texto final da Primeira Epístola de Paulo a Timóteo no capítulo 3, verso 16: "Aquele que foi manifestado na carne foi justificado em espírito, contemplado por anjos, pregado entre os gentios, crido no mundo, recebido na glória".

Semelhantemente, o texto mais amplo que se encontra no capítulo 4 da Primeira Epístola de Pedro, iniciado no verso 16 do capítulo 3 e estendido até o verso 6 do capítulo 4, contém os elementos básicos de uma dessas antigas declarações de fé que poderiam ter dado origem ao que posteriormente foi chamado de "Credo Apostólico". Dentre eles podem ser destacados os seguintes:

- Morte de Cristo (3:18) - "Pois também Cristo morreu, uma única vez, pelos pecados..." .

- Ressurreição (3:22) - "O qual, depois de ir para o céu ...".

- À direita de Deus (3:22) - "Está à destra de Deus".

- Juízo dos vivos e dos mortos (4:5) - "Aquele que é competente para julgar vivos e mortos"

Todos os Credos incorporados ao Cristianismo primitivo (Credo Niceno, Credo Atanasiano e outros), cujas declarações permanecem até hoje nas Igrejas Cristãs (Católica, Ortodoxa, Reformadas, etc.) enfatizam logo de início a crença no Deus Criador com as palavras "Creio em Deus Pai, todopoderoso, Criador dos céus e da terra", testemunhando que a percepção do Deus Criador sempre continuou central no Cristianismo.

É digno de nota que, após a crença no Deus Criador, passa a ser ressaltada nos Credos do Cristianismo a crença no Filho Unigênito de Deus, que veio ao mundo para salvar os que se haviam perdido. A pregação bíblica, assim, está firmada sobre os dois grandes pilares inamovíveis e interdependentes - a Criação e a Redenção.

\section{A percepção do deus criador nos últimos días}

Reportando-me agora aos tempos em que estamos vivendo, deve ser ressaltado que, a partir de meados do século XIX, desenvolveu-se o Epicurismo Moderno, com a pregação da filosofia evolucionista gradativamente insinuada 
em todos os campos do saber e da atividade humanos. Torna-se claro que o objetivo básico dessa pregação é contrapor-se à percepção do Deus Criador que, como já destacado, apesar de também ter sido contraposta, não só esteve incorporada nas crenças das mais antigas civilizações e exposta e defendida por filósofos pagãos, como também revelada nas Escrituras.

Não seria surpresa, então, que no grande conflito entre o bem e o mal surgisse a tentativa de desmerecer a revelação dada na Bíblia sobre a atividade criadora de Deus, pois ao ser ela desacreditada ruiria um dos dois grandes pilares da pregação do Evangelho, levando também à ruína o segundo pilar interdependente.

E, de fato, essa tentativa surgiu de forma específica a partir da data histórico-profética de 1844, em que começa a pregação evolucionista na Biologia e na Geologia, daí se estendendo de forma abrangente aos demais campos da Ciência, visando solapar os fundamentos do segundo pilar. É particularmente notável, nesse sentido, a declaração de Charles Darwin na Introdução de seu livro "A Origem das Espécies", transcrita a seguir:

"Depois de cinco anos de um trabalho pertinaz, redigi algumas notas; em seguida, em 1844 (ênfase adicionada), resumi estas notas em forma de memória, onde indicava os resultados que me pareciam oferecer algum grau de probabilidade".

Certamente não por mera coincidência, é também a partir dessa mesma data que se inicia o maior movimento de restauração da verdade sobre o Deus Criador que em breve há de regenerar toda a Sua criação! Esse movimento foi prefigurado profeticamente no texto de Apocalipse 14:6-7:

"Vi outro anjo voando pelo meio do céu, tendo um evangelho eterno para pregar aos que se assentam sobre a terra, e a cada nação, tribo, língua e povo, dizendo com grande voz: Temei a Deus e dai-Lhe glória, pois é chegada a hora do Seu juízo; e adorai Aquele que fez o céu, e a terra, e o mar e as fontes das águas".

A propósito, deve ser destacado que "a hora de Seu juízo" citada nos versículos acima é um momento inequivocamente determinado, com precisão impressionante, da ordem de minutos, a partir de dados históricoproféticos, cronológicos e astronômicos, como sendo um dia determinado no ano de 1844! (Darwin, 1987). 
Ruy Carlos de Camargo Vieira

A abrangência do conflito que se estabeleceu a partir de meados do século XIX em torno da pregação sobre o Deus Criador revelado nas Escrituras - cujas raízes. em particular, foram lançadas em 1844 - é algo que verdadeiramente nos deixa profundamente impressionados, e a esse respeito desejo ressaltar a aparente fortuita coincidência entre os acontecimentos profetizados e a realidade histórica vivida desde então.

Assim, no texto de Apocalipse 14:6-7 podem ser consideradas as seguintes palavras-chave que caracterizam os pontos altos referentes à percepção do Deus Criador e o Seu propósito redentor nos últimos dias da História deste nosso mundo:

- Pregação do Evangelho Eterno

- Hora de Seu Juízo

- Adoração ao Criador

Semelhantemente, em contraposição a esse movimento de restauração da percepção do Deus Criador, passaram a entrar em cena modernamente também os seguintes eventos mais significativos:

- O "Movimento Socialista" para a salvação do mundo - um novo "evangelho" em substituição ao Evangelho Eterno, caracterizado precipuamente nas publicações:

1847 - "O Capital" de Karl Marx, divulgando uma doutrina que se transforma em um novo "Evangelho" ateísta;

1848 - "Manifesto Comunista" de Marx e Engels, estabelecendo uma doutrina materialista baseada na evolução e na revolução sociais visando à "salvação" do mundo.

- O “Movimento Espiritualista" para a salvação do mundo - evolução anímica em substituição ao juízo e morte vicária de Cristo, caracterizada exemplarmente nos acontecimentos:

1844 - Experiência espiritual de Andrew Jackson Davis, a partir da qual passa a ser introduzida a doutrina de reencarnações sucessivas para a evolução do ser humano, negando e substituindo a necessidade da regeneração do velho homem para receber a salvação pelos méritos de Cristo;

1844 - Manifestações espirituais em Hydesville, a partir das quais passa 
a ser introduzida a doutrina da evolução anímica em direção à perfeição, pelos méritos próprios, em substituição à salvação pela graça.

- O "Movimento Evolucionista" para explicar a criação do mundo - evolução natural geológica e biológica em substituição à criação e ao Criador revelados na Bíblia, caracterizado inicialmente nas publicações:

1844 - "Vestiges of the Natural History of Creation" de Robert Chambers introduzindo a doutrina da transformação das espécies, em substituição à criação das espécies;

1844 - "The Origin of Species" de Charles Darwin introduzindo a doutrina da evolução das espécies pela atuação da Seleção Natural, em substituição à criação original das espécies.

Não deixa de ser interessante que essas substituições da verdade revelada nos textos bíblicos, pelas diferentes doutrinas espúrias, sejam doutrinas ateístas, contra as quais, para os fieis adoradores de Deus se encontra o alerta dado em I Timóteo 4:1:

Ora, o Espírito afirma expressamente que, nos últimos tempos, alguns apostatarão da fé, por obedecerem a espíritos enganadores e doutrinas de demônios.

Fica claro, também, que a razão e a urgência apontadas em Apocalipse 14:6-7 para ser dada glória a Deus se insere no contexto da moderna pregação sobre o Deus Criador a ser levada a todos os recantos da Terra, cumprindo a profecia de Mateus 24:14 sobre a pregação do Evangelho a todo o mundo, sob a perspectiva do Seu mérito, como também é ressaltado no texto de Apocalipse 4:11:

Tu és digno, Senhor e Deus nosso, de receber a glória, a honra e o poder, porque todas as coisas Tu criaste, sim, por causa da Tua vontade vieram a existir e foram criadas.

E para finalizar este apanhado geral, não posso deixar de citar as seguintes passagens bíblicas:

- $\quad$ Apocalipse 10:5-6 - Então o anjo que vi em pé sobre o mar e sobre a terra levantou a mão direita para o céu e jurou por Aquele que vive 
Ruy Carlos de Camargo Vieira

pelos séculos dos séculos, o mesmo que criou o céu, a terra, o mar e tudo quanto neles existe: Já não haverá demora.

- S. Lucas 21:28 - Ora, ao começarem estas coisas a suceder, exultai e erguei a vossa cabeça; porque a vossa redenção se aproxima.

Que privilégio sermos arautos dessa verdade "uma vez entregue aos santos" (Judas v. 3)!.

\section{Conclusão}

Pensemos mais profundamente na percepção deste Deus Criador em conexão com Seu amorável Plano de Redenção, e em como essa percepção deve e pode afetar nossa vida.

Da mesma maneira, pensemos sobre qual deve ser o nosso papel a ser desempenhado na pregação da mensagem sobre esse Deus Criador nestes tempos em que vivemos, ao sobrevir a avassaladora onda evolucionista e materialista contrapondo-se à revelação dada por Deus desde o início para os seres humanos que Ele mesmo criou, mas que no decorrer do tempo cada vez mais a corromperam e degradaram.

Termino, destacando o pensamento poético de Paulo, que se encontra em seu "Hino de Adoração" apresentado em Romanos 11:33-36, sobre este Deus Criador:

Ó profundidade da riqueza, tanto da sabedoria como do conhecimento de Deus! Quão insondáveis são os Seus juízos, e quão inescrutáveis os Seus caminhos!

Quem, pois, conheceu a mente do Senhor?

Ou quem foi o Seu conselheiro?

Ou quem primeiro deu a Ele para que Ihe venha a ser restituído?

Porque dEle, e por meio dEle, e para Ele são todas as coisas.

A Ele, pois, a glória eternamente. Amém. 


\section{Referências}

Barnes, J. (1987). Early Greek Philosophy. Harmondsworth: Penguin Classics.

Budge, W. (1969). The Gods of the Egyptians. Vol. 1. New York: Dover.

Brown, N. (1953). Hesíodo. Theogony. New York: Bobbs-Merril Co.

Darwin, Ch. (1987). A Origem das Espécies. Sao Paulo: Hemus Livraria Editora Ltda.

Lee, D. (1965). Platão. Timaeus and Criteas. Harmondsworth: Penguin Classics.

Lund, E. (1976). A History of European Ideas. London: C. Hurst \& Co.

McGregor, H. Tr. (1988). On the Nature of the Gods. Harmondsworth: Penguin Classics.

Oliveira, J. (2004). , Chronological Studies Related to Daniel 8:14 and 9:24-27. Sao Paulo: UNASPRESS.

Saunders, T. Tr. (1970). Platão. The Laws. Harmondsworth: Penguin Classics.

Wieger, L. Tr. (1991). Lao-Tzé. Tao-te-ching. Versão inglesa por Derek Bryce. Lampeter: Llanerch Plublishers. 